\title{
The Role of Social Participation in Controlling and Preventing of Coronavirus 2019 Disease in Iran
}

\author{
Morad Ali Zareipour*, Jila Nagavi Kalejahi \\ Health System Research Unit, Health Center of Urmia, Urmia University of Medical Sciences, Urmia, Iran
}

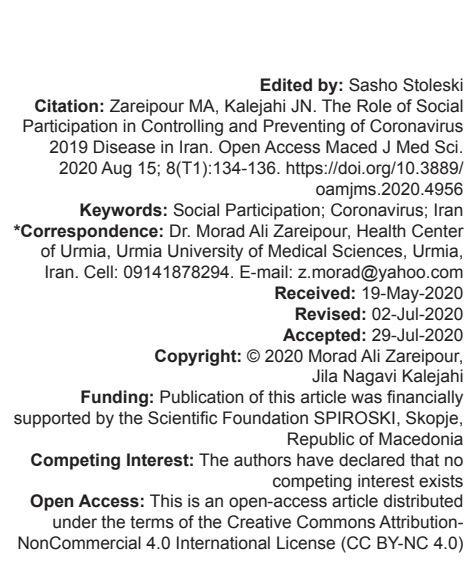

\section{Introduction}

The coronavirus is spreading rapidly around the world these days, and many countries are infected around the world. Coronavirus is actually a large family of viruses that lead to respiratory infections from a simple cold to the severe acute respiratory syndrome (SARS) epidemic which was spread in 2019. And now coronavirus 2019 disease (COVID-19), the newest member of the family known as the Corona in Iran, is expanding rapidly [1], [2].Corona pandemics is currently one of the most important health issues in the world [3]. The number of COVID-19 cases in the world has increased significantly compared to SARS and MERS, and it may take some time to reduce the incidence of the disease. This means that control measures must be in place for a longer period of time [4].The health system of Iran and Iranian society has been severely affected by this pandemic [5].

Due to the severity of the disease, the health system has plans to deal with the disease. However, due to the wide dimensions of the disease, there will be a lot of work pressure on the health-care system, which may not be able to compensate for its dimensions in various aspects. Those aspects include economic problems, social anxiety and lack of response of the health system to patients. Therefore, the participation and cooperation of the society in the form of mobilizing the society with the health system will be effective in controlling and preventing this disease.

\section{Social Partnership}

Social participation requires the participatory action of all citizens of a neighborhood to achieve control and influence on the determinants of health in that neighborhood, which is one of the important goals in the sustainable development of communities [6]. Social participation is the conscious, voluntary, spontaneous, and purposeful participation of groups and individuals in the processes and social affairs of the society to share and play a role in the work, facilitate and expedite the affairs of the society and exploit their results and help the 
goals of social development [7]. In today's society, social participation can be divided in the form of five dimensions political, social, economic, physical, and cultural, and the role and presence of the people and local communities are very important at each of its levels. If governments and the health system target the local community and consider citizens with potential capabilities and prioritize the discovery and development of their capabilities, we will undoubtedly be able to move forward on the path of development. This form of participations is pursued by local and national governments to coordinate and facilitate neighborhood-based efforts to be followed by innovation, plan, and implementing projects in principled ways to determine the path by the community itself, to organize by the community itself, and to manage the process by the community itself [8], [9].

The result of participation in this area is the development of the local community, which is a kind of approach to development from below. In this view, the development of the local community will be a factor of success and promotion if it is achieved by nongovernmental organizations. Therefore, this requires mobilizing the endogenous capabilities of society [10]. In this regard, the use of social participation should be considered as one of the basic capabilities of society in planning. In fact, it is social participation that ensures the formation of a society in the true sense, and forms the concept of social cohesion that restores the amount and quality of interaction and social relations and the strengthening of social networks in society. Thus, participation with a community-based approach takes action in the field of community health in a wide variety of areas, including institutional capacity building, basic skills development, entrepreneurial group formation, poverty reduction programs, reducing risky behaviors and social harms, and education (including people, managers, and facilitators) [11].

The most obvious benefit of social participation, which has been addressed in various sources, is the improving of people's sense of responsibility and awareness toward the individual and collective health. Another advantage is the acquisition of power through the creation of new skills and the power of resource's control. In fact, the participants train themselves and their neighborhood to control their own and their neighborhood's destiny, and provide equal opportunities between themselves and health-care providers [6]. In the process of participation in health, the opportunity of health knowledge distribution in society is created and led the internal acquisition of mastery in promoting public health. Furthermore, the percentage of supply of resources will increase and the cost of spending will decrease and the possibility of accumulating of available resources and access to them will be possible; at the same time, the allocation of resources will be facilitated for the needy. A better understanding of the health and well-being needs of the people and the promotion of health are other benefits of people's participation in health affairs. The involvement and active participation of the local people increases the sense of social responsibility and eliminates the sense of authority and dominance of official organizations. All of these outcomes have a positive effect on the health of people and society [7]. The quality of people behave in an emergency occasions depends on their understanding and their assessment of risk and their vulnerability. In general, the perception of disaster risk is considered as a commensurate behavior in risks so that the negative consequences of disasters are related to low risk perception [5]. Shortly, after the initial shock caused by the coronavirus outbreak in the country, we have witnessed the formation of social participation movements in various forms and methods by people all around the country.

\section{COVID-19 \\ Some example of social participation in}

Distribution of masks and free health packages among people by donors across the country, voluntary cooperation of people with medical staff, preparation of food packages for families of coronavirus patients by people and donors, installation water faucets and placing handwashing liquid on the side of the street by some shopkeepers for public use, food preparation and accommodation for the staff of the involved hospitals, accepting the cost of training packages to prevent coronavirus, informing best ways to prevent the disease with a free speaker by personal vehicle, and another aspect of social participation is the support of individuals and businesses that are not booming these days due to the current state of emergency.

Non-governmental organizations and associations can take the necessary supportive measures at this time by brainstorming, invitation the support of benefactors, helping to identify the needy, and the financially disadvantaged. Let's not forget that social participation is usually spontaneous during crises such as floods and earthquakes and epidemics such as cholera, it occurs spontaneously at this time. However, all of these actions will be significant along with the efforts of health officials and the concerted efforts of government officials to curb the disease and its effects.

\section{Conclusion}

Since a common goal is formed in social participation, a common motivation to achieve that goal can be a stimulus for inclusive determination to curb crises and lead to effective collective action in the light of accurate and timely awareness and informing. Hence, social participation can certainly counteract coronavirus. Concepts such as empathy and social participation have extra meaning today, 
and out of despair and hopelessness, we can hope to more developments in the field of medical science and service delivery in various fields of health and treatment and attention to the deprived individuals.

\section{References}

1. Yang $Y$, Shang W, Rao X. Facing the COVID-19 outbreak: What should we know and what could we do? J Med Virol. 2020;92(6):536-7. https://doi.org/10.1002/jmv.25720 PMid:32091134.

2. Kolifarhood G, Aghaali M, Saadati HM, Taherpour N, Rahimi S, Izadi N, et al. Epidemiological and clinical aspects of Covid-19; a narrative review. Arch Acad Emerg Med. 2020;8(1):e41. PMid:32259130.

3. Lipsitch M, Swerdlow DL, Finelli L. Defining the epidemiology of Covid-19 studies needed. N Engl J Med. 2020;382(13):1194-6. https://doi.org/10.1056/nejmp2002125

4. Kelly-Cirino C, Mazzola LT, Chua A, Oxenford CJ, Van Kerkhove MD. An updated roadmap for MERS-CoV research and product development: Focus on diagnostics. BMJ Glob Health. 2019;4 Suppl 2:e001105. http://dx.doi.org/10.1136/ bmjgh-2018-001105

PMid:30815285
5. Samadipour E, Ghardashi F. Factors influencing Iranians' risk perception of Covid-19. J Mil Med. 2020;22(2):122-9. https://doi. org/10.30491/JMM.22.2.122

6. Bath J, Wakerman J. Impact of community participation in primary health care: What is the evidence? Aust J Prim Health. 2015;21(1):2-8. https://doi.org/10.1071/PY12164

7. Piškur B, Daniëls R, Jongmans $M J$, Ketelaar $M$, Smeets RJ, Norton $\mathrm{M}$, et al. Participation and social participation: Are they distinct concepts? Clin Rehabil. 2014;28(3):211-20. https://doi. org/10.1177/0269215513499029

PMid:23988324.

8. Gatewood JG, Litchfield RE, Ryan SJ, Geadelmann JD, Pendergast JF, Ullom KK. Perceived barriers to communitybased health promotion program participation. Am J Health Behav. 2008;32(3):260-71. https://doi.org/10.5993/AJHB.32.3.4.

9. Frankish CJ, Kwan B, Ratner PA, Higgins JW, Larsen C. Challenges of citizen participation in regional health authorities. Soc Sci Med. 2002;54(10):1471-80. https://doi.org/10.1016/ S0277-9536(01)00135-6

PMid:12061482.

10. Hyyppä MT, Mäki J. Social participation and health in a community rich in stock of social capital. Health Educ Res. 2003;18(6):770-9. https://doi.org/10.1093/her/cyf044

11. Goss C, Mosconi P, Renzi C, Deledda G. Participation of patients and citizens in healthcare decisions in Italy. Z Evid Fortbild Qual Gesundheitswes. 2011;105(4):277-82. https://doi.org/10.1016/j. zefq.2011.04.003

PMid:21620321 